\title{
GA vs no GA
}

\section{Opinion}

A study I conducted a few years ago in order to detect the tendency to refer young patients to the hospital to perform a Comprehensive Dental Treatment (CDT) under General Anesthesia (GA). The survey included 38 Dentists Specialists used to practice CDT under GA and the Intravenous (IV) sedation technique I choose to divide the practitioners into 2 age groups. The first group is the young age 40 or less and the second one is the old age group 40 plus. The child patients are divided into 3 groups:

1. Up to 5 years old

2. From 5 to 8 years old

3. 8 and up

The assumed selected patients should follow specified criteria, they are uncooperative children" classified Frankl IV" and the number of teeth to be treated should not be less than 4 one of them in
Volume 6 Issue 3 - 2017

\section{Sadek Bakdach}

Department of Pediatric Dentistry, Paris Academy, USA

Correspondence: Sadek Bakdach, Department of Pediatric Dentistry, Paris Academy, 4058 State St, Saginaw, MI 48603, USA, Email sadekbakdach@gmail.com

Received: February 08, 2017 | Published: February 08, 2017 critical condition or suffering from bad esthetic. Clear GA cases like "Children with special needs and extreme urgent cases" are excluded.

\section{At what percentage do you estimate the need for GA?}

The result shows the following (Table 1)

Table I At what percentage do you estimate the need for GA?

\begin{tabular}{|c|c|c|}
\hline Doctors in favor of the GA patients age groups & Group A 40 Y.O. Or Less & Group B + 40y.O \\
\hline Group I & $54 \%$ & $63 \%$ \\
\hline Group II & $47 \%$ & $57 \%$ \\
\hline Group III & $32 \%$ & $41 \%$ \\
\hline $\begin{array}{l}\text { 2-How do you evaluate the clinical outcome of the GA } \\
\text { cases? }\end{array}$ & $90 \%$ v. good & $75 \%$ v. good \\
\hline 3-How many cases required a redo GA? & less than $1 \%$ & I to $1,5 \%$ \\
\hline $\begin{array}{l}\text { 4-how many cases required clinical visits for new } \\
\text { treatment soon after the GA? }\end{array}$ & $12 \%$ & $11 \%$ \\
\hline
\end{tabular}

\section{What are the hurdles limiting the number of the GA cases?}
a. All agree on:
b. The High cost
c. The parents acceptance/refusal of the GA
d. Ignorance and/or exaggerating the risk factors in a negative way

I will not conclude my study with any recommendation or statistics; I will leave it to the reader's judgment.
The big remaining question is;

Is the IV sedation technic a good and reliable solution?

The answer needs new studies and open discussions.

\section{Acknowledgments}

None.

\section{Conflicts of interest}

The authors declare that there is no conflict of interest. 